\title{
Ionospheric signatures of magnetospheric boundaries in the post-noon sector
}

\author{
S. T. Berry ${ }^{1}$, L. Kersley ${ }^{1}$, J. Moen ${ }^{2, *}$, W. F. Denig ${ }^{2}$ \\ ${ }^{1}$ Department of Physics, University of Wales, Aberystwyth SY23 3BZ, UK \\ E-mail: lek@aber.ac.uk \\ ${ }^{2}$ Air Force Research Laboratory, Space Vehicles Directorate, Hanscom AFB, MA01731, USA
}

Received: 5 January 1999 / Revised: 18 August 1999 / Accepted: 27 August 1999

\begin{abstract}
Spatial structures in ionospheric electron density revealed in a tomographic image have been identified with auroral forms and related to their sources in precipitating particles observed by DMSP satellites. The observations of plasma enhancements relate to discrete auroral arcs seen in the post-noon sector, identified by both red- and green-line emissions measured by a meridional scanning photometer. The features lie within a very narrow latitudinal band on $L$-shells where the satellite detectors observed electron precipitation classified as from the boundary plasma sheet (BPS). The harder particles are identified with an E-region structure, while further north the precipitation is softer, resulting in a localised F-layer blob and $630.0 \mathrm{~nm}$ emissions. A steep gradient in plasma density represent a signature in the ionosphere of the central plasma sheet (CPS)/BPS boundary. A transition to a less-structured F-layer is found on crossing the convection reversal boundary.
\end{abstract}

Key words. Ionosphere (auroral ionosphere; ionosphere-magnetosphere interactions; polar ionosphere)

\section{Introduction}

The classification of magnetospheric boundary regions in terms of particle precipitation characteristics has been discussed extensively in recent years. Newell et al. (1991) used low-altitude satellite observations to categorise dayside precipitation into four different regimes. They established criteria for identification of four regions with

Correspondence to: L. Kersley

* On leave from Arctic Geophysics, University Courses on Svalbard (UNIS), N-9170 Longyearbyen, Norway different fluxes and spectra of ions and electrons in the dayside sector: the extension of the boundary plasma sheet (BPS), the low latitude boundary layer (LLBL), the cusp proper, and the plasma mantle. Newell and Meng (1992) presented a statistical mapping of particles with different characteristics from the magnetosphere and magnetosheath into the high-latitude ionosphere. In the post-noon sector, they showed an extension of the BPS nightside precipitation separating the LLBL and the plasma mantle from the harder particles associated with the ring current of the central plasma sheet (CPS), implying that the particles are accelerated on newly closed field lines in the tail.

Auroral activity in the 14 to 16 MLT sector has been attributed to both BPS and LLBL precipitation (Moen et al., 1994, 1995; Sandholt et al., 1998). At this time, when the upward region 1 field-aligned current is at a maximum (Iijima and Potemra, 1978), the aurora usually consist of narrow discrete forms that are aligned east-west (Meng and Lundin, 1986). Evans (1985) used satellite measurements to show that the precipitation in the sector appears in general as multiple, latitudinallythin $(\sim 20 \mathrm{~km})$ structures of electrons with energies $<3 \mathrm{keV}$, and he suggested that this category of postnoon auroral activity is likely to be associated with direct solar wind-magnetosphere interaction.

Robinson et al. (1984) used incoherent scatter measurements of an F-region electron density enhancement, co-located with an upward field-aligned current, to demonstrate the ionospheric response to precipitation. Moen et al. (1994) demonstrated that the auroral arcs were in sunward convecting flow, to the equatorward side of the reversal boundary. They suggested that the activity may be related to Kelvin-Helmholtz instabilities operating at the edge of the LLBL or to perturbations in the magnetopause pressure balance. In a more general study over a wider time period, Troshichev et al. (1996) proposed that the discrete features lie on closed field lines in the sunward return flow, equatorward of the convection reversal. In addition, they argued that the source of the upward region-1 currents may lie close to 
the boundary separating the diffuse auroral precipitation of hard CPS electrons from the discrete softer electrons of the BPS. Recently, Lockwood (1997) modelled ion precipitation around magnetic noon, showing that the BPS precipitation was on recently opened field lines and arose from the interior Alfven wave at the magnetopause. He drew a clear distinction between this dayside BPS and the extension of the nightside BPS that resulted from acceleration in the tail current sheet.

Moen et al. (1998) demonstrated that ionospheric tomography could be used to examine the E- and F-layer ionisation caused by energetic particle precipitation responsible for the discrete aurora. Narrow, fieldaligned structures were observed in the latitudinal distribution of the electron density that were related to optical observations of red- and green-line auroral emissions. The current study takes the experimental observations a stage further by relating the response in ionospheric electron density, not just to the discrete auroral activity in the post-noon sector, but also to its source in structured BPS precipitation identified by lowaltitude DMSP satellite observations. It is shown that radio tomographic imaging of ionospheric structures provides evidence for the mapping of discrete features and the identification of boundaries between different magnetospheric regimes.

\section{Instrumentation}

\subsection{Ionospheric tomography}

Phase-coherent radio signals on 150 and $400 \mathrm{MHz}$, transmitted by satellites of the Navy Ionospheric Monitoring System (NIMS), are monitored at a latitudinal chain of ground-based receivers, measuring the total electron content (TEC) along many intersecting ray paths. The tomographic procedure uses an inversion algorithm to produce an image of the spatial distribution of the electron density as a function of latitude and height. Further information on the development of experimental ionospheric tomography has been given by Kersley and Pryse (1994) and Walker et al. (1996). The reconstructions described in the present work were obtained using a modified version of the discrete inverse theory (DIT) method of Fremouw et al. (1996) to create the large-scale features, with details in the final image being revealed in subsequent processing by the algebraic reconstruction technique (ART) (Gordon et al., 1970). The locations of the four satellite receiving stations were at Tromsø $\left(69.8^{\circ} \mathrm{N}, 19.0^{\circ} \mathrm{E}\right)$, Bjørnøya $\left(74.5^{\circ} \mathrm{N}, 19.0^{\circ} \mathrm{E}\right)$, Longyearbyen $\left(78.2^{\circ} \mathrm{N}, 15.7^{\circ} \mathrm{E}\right)$ and $\mathrm{Ny}$ Alesund $\left(78.9^{\circ} \mathrm{N}, 11.9^{\circ} \mathrm{E}\right)$.

\subsection{Optical instrumentation}

The latitudinal position of the discrete auroral forms studied in the present work was obtained from observations made by the meridian scanning photometer
(MSP) at Ny Ålesund. This instrument monitors both the green $(557.7 \mathrm{~nm})$ and red $(630.0 \mathrm{~nm})$ emissions during scans along the geomagnetic meridian, between elevations of $10^{\circ}$ above each horizon, with a cycle time of $18 \mathrm{~s}$.

\subsection{Low-altitude satellite particle data}

The spectral characteristics of particle precipitation have been obtained from detectors aboard two DMSP satellites, in Sun-synchronous, nearly-circular orbit at about $835 \mathrm{~km}$ altitude. The electrostatic analyser measures the fluxes of electrons and ions with energies between $32 \mathrm{eV}$ and $30 \mathrm{keV}$, observing only highly fieldaligned particles well within the loss cone.

\section{Observations}

Figure 1 shows observations of auroral emissions at $630.0 \mathrm{~nm}$ and $557.7 \mathrm{~nm}$ made by the meridian scanning photometer (MSP) at Ny Alesund on 17 December, 1996, around 1100 UT ( 14 MLT). Each of the stacked traces represents a single scan of the photometer, along the geomagnetic meridian. At the time of interest, coincident with a NIMS satellite pass, the emissions were dominated by intense green aurora north of zenith, that was stable for more than five minutes with a double peak intensification at around $1103 \mathrm{UT}$, the time that the satellite was transiting the Ny Alesund zenith. In addition, the $630.0 \mathrm{~nm}$ red-line emissions indicate a

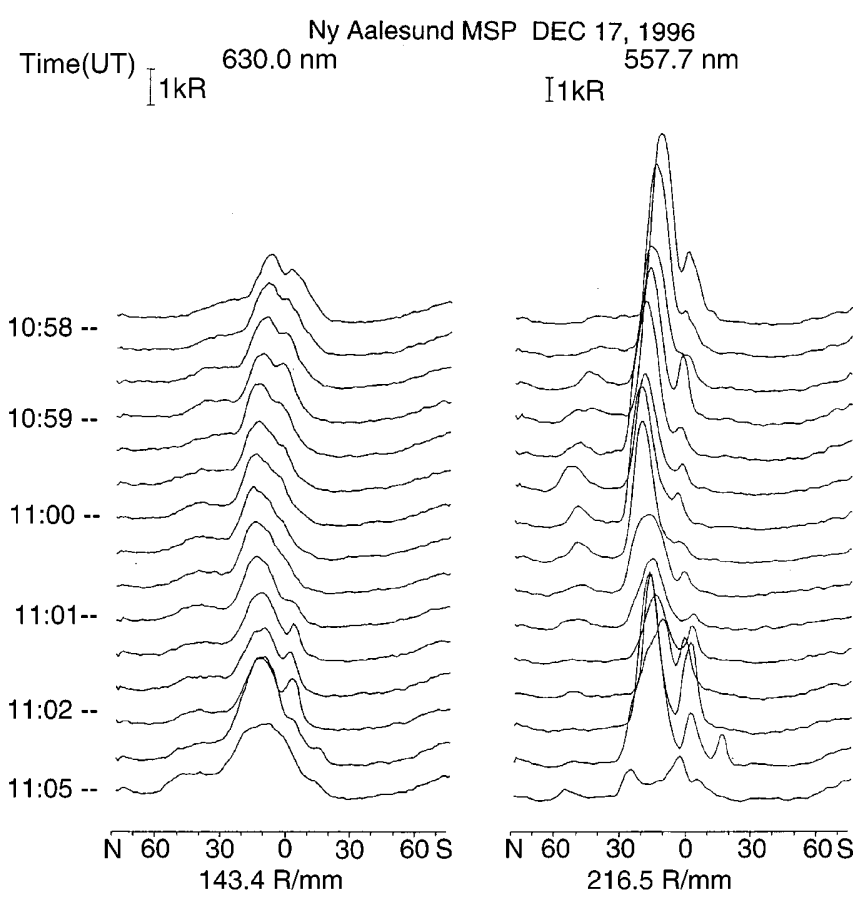

Fig. 1. Stacked plot observations of red- $(630.0 \mathrm{~nm})$ and green$(557.7 \mathrm{~nm})$ line auroral emissions from the meridional scanning photometer at Ny Ålesund made around 1100 UT on 17 December, 1996 
broader region of emission extending north from the zenith at this time, also with a weaker second peak just south of zenith developing after $1101 \mathrm{UT}$. It must be recalled that the lifetime of the excited state is $110 \mathrm{~s}$ for the red-line emission, so that there is a lag in the observed response to energy input in the F-layer, in contrast to the more immediate optical signature of the green-line at E-layer heights.

The response of the ionospheric electron density to the aurora is seen in Fig. 2. This shows a tomographic reconstruction obtained from observations of the NIMS satellite pass with a southbound crossing of $75^{\circ} \mathrm{N}$ at $1106 \mathrm{UT}$. The image, plotted over the range $72^{\circ} \mathrm{N}$ to $84^{\circ} \mathrm{N}$, depicts a dayside trough with a minimum about $77^{\circ} \mathrm{N}$ and a steep gradient to the north, leading to a structured F-layer enhancement between about $78.5^{\circ} \mathrm{N}$ and $81.5^{\circ} \mathrm{N}$. There are reduced electron densities in a smoother ionosphere at the northern extremity of the image. The densities in the most enhanced feature maximise at a height of around $210 \mathrm{~km}$ and show evidence of field alignment, taking into account a geometrical distortion in the image arising because the satellite pass was to the east of the receiver chain.

By assuming an emission altitude of $250 \mathrm{~km}$ in the F-region for the red-line aurora and $120 \mathrm{~km}$ for the E-layer, green auroral forms, it is possible to calculate the location of the arcs in geomagnetic co-ordinates, thus attributing ionospheric plasma density features to particular auroral events. The E-layer feature in Fig. 2 demonstrates very close correspondence with the $557.7 \mathrm{~nm}$ aurora just north of zenith in Fig. 1. In the F-region, the plasma blob at around $79.5^{\circ} \mathrm{N}$ lies in the region of maximum $630.0 \mathrm{~nm}$ red-line emissions from 1057 UT onwards. The secondary enhancement at around $79^{\circ} \mathrm{N}$ corresponds to the intensification of the red aurora in the zenith at about 1101 UT. There is also evidence for a weaker green-line emission close to zenith, though the E-layer densities are not resolved in the image. The pixel size used for the reconstruction was about $25 \mathrm{~km}$. In addition, it must be noted that the tomographic technique requires observations to be made for a range of ray-path geometries over a period of several minutes. It is estimated that the time period of interest for the imaging of the structures considered above extended for some 3 to $5 \mathrm{~min}$ before $1103 \mathrm{UT}$, so that there is some integration of the temporal evolution of the electron density in the image. This is of particular relevance to E-layer heights, where the time constants are generally on the scale of minutes. However within these constraints, it can be concluded that there is good agreement between the optical emissions and the plasma structures.

Information on particle precipitation and convective flows affecting the ionosphere shown in the tomographic reconstruction has been obtained from passes of DMSP satellites. Between 11:02:00 UT and 11:09:00 UT, the DMSP-F13 satellite traversed the dayside region to the north of Svalbard in a dusk-to-dawn trajectory reaching $81^{\circ} \mathrm{N}$ MLAT near the noon meridian. Figure 3a shows the electron and ion precipitation fluxes, together with the on-board magnetometer data for the overpass. A clear boundary between the region of hard $(>10 \mathrm{kev})$ electron precipitation characterising the central plasma sheet (CPS) and softer, discrete boundary plasma sheet (BPS) type particles, is evident at about $75.0^{\circ} \mathrm{N}$ MLAT just after 1102 UT. The BPS precipitation continues to a second sharp transition at around $78.0^{\circ} \mathrm{N}$ MLAT before 1104 UT, which probably represents the satellite entering the polar cap, where the flux and energy of the electrons drops rapidly. This polar-cap regime continues until the satellite emerges on the morningside, where it encounters BPS-type activity after 1107 UT.

Variations in the local magnetic field on F13 can be used to determine the ionospheric field-aligned currents
Tomographic Image: 17/12/96 11:06 UT

\section{Electron Density $\left(\mathrm{x}_{10} 0^{11} \mathrm{~m}^{-3}\right)$}

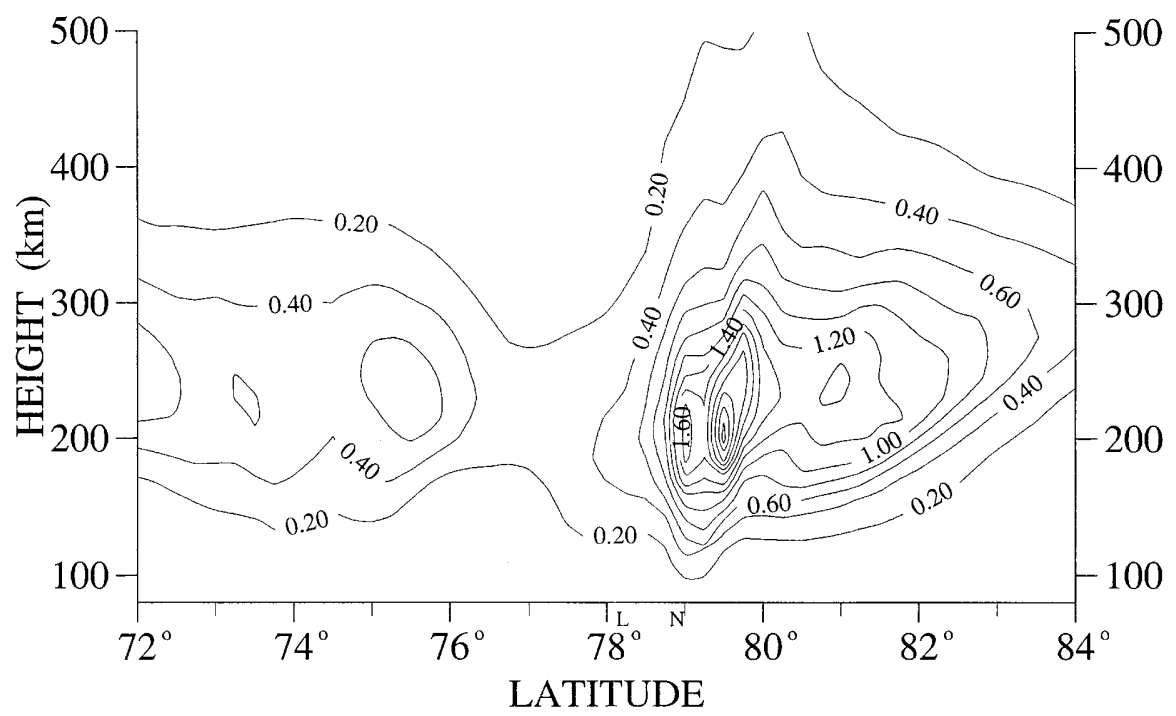

Fig. 2. Tomographic image of electron density reconstructed from observations of a southbound satellite pass that crossed $75^{\circ} \mathrm{N}$ at 1106 UT on 17 December, 1996 
F13 17 Dec 1996

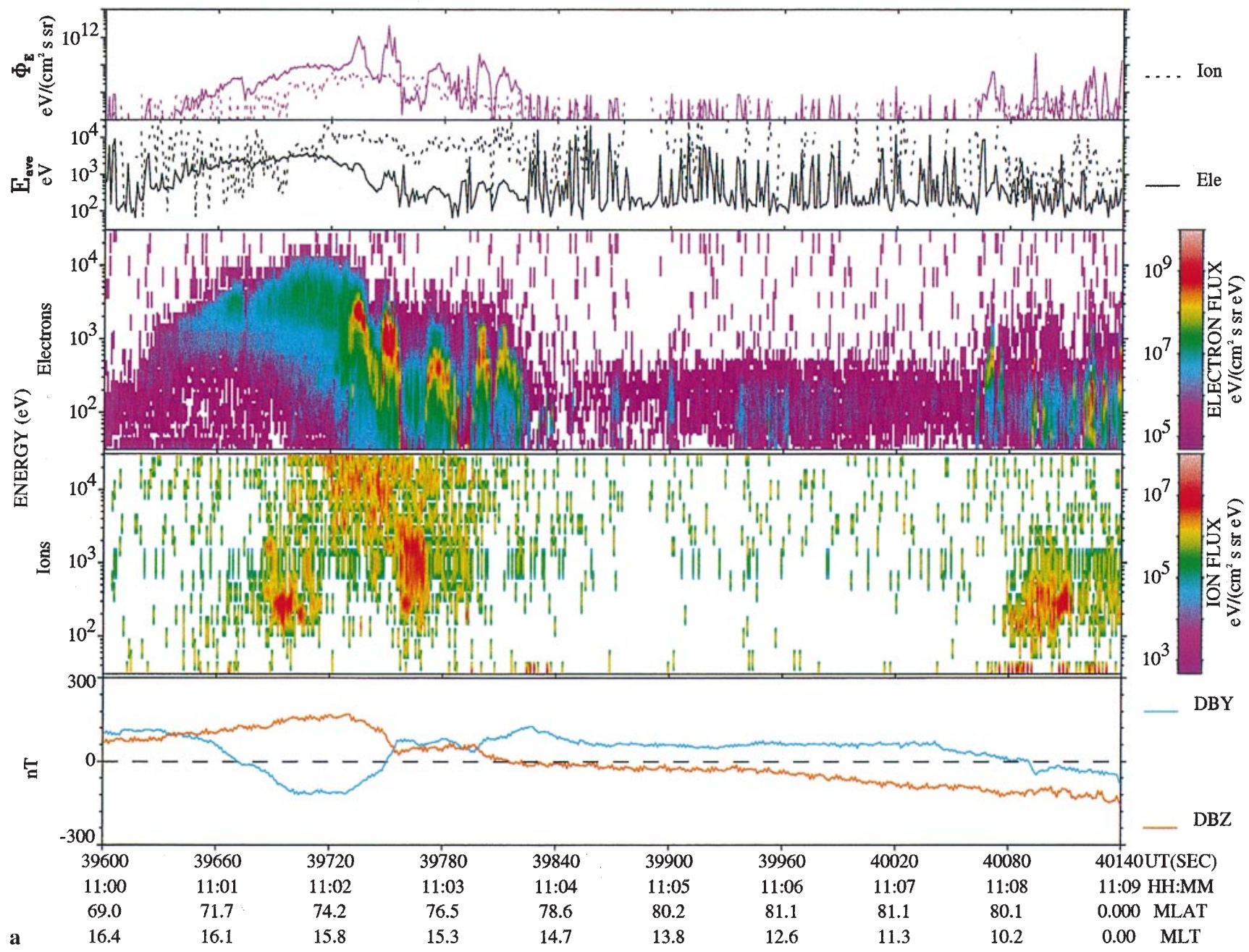

Fig. 3a, b. Spectra of precipitating electrons and ions measured by DMSP satellites during passes near Svalbard on about 1100 UT on 17 December, 1996, a satellite F13 and b satellite F12

and to infer patterns of local convection. The data presented in the lower panel of Fig. 3a, represent the difference between the measured field and the modelled field (IGRF-95) in the horizontal components, DBY and DBZ. In general, for F13 in the Northern Hemisphere, a negative (positive) slope in the DBY (DBZ) indicates that F13 traversed a downward current sheet whereas a positive (negative) slope in DBY (DBZ) indicates an upward current sheet. The observations in Fig. 3a show that a downward current was located between 1101 and about 1102 UT and an upward current between from about 1102 until 1104 UT, a rather strong region 1 current that decreased in strength yet could, nevertheless, be detected until 1104 UT. Our interpretation of these data is that a downward, afternoon region 2 fieldaligned current was located within the measured CPS and an extended, upward region 1 field-aligned current was within the region of BPS precipitation. It can be inferred from these data that the convective drift was generally sunward in the region containing the region $1 /$ region 2 current system and that the convection reversal was at the poleward edge of the region 1 current, between 1103 UT and 1104 UT, where the slope on the DBY turned negative at the edge of the BPS precipitation.

A second coincident pass was that of DMSP-F12, which traversed the region from north-east to south west. The associated spectrogram and magnetometer observations are displayed in Fig. 3b, showing conditions between 1100 UT and 1109 UT as the satellite crossed the dusk to post-noon sector from about 19 MLT to 13 MLT. The magnetic field data for this pass can be used to identify the eveningside region 1 /region 2 current sheets, around 1102 UT, and the afternoon region 1 /region 2 system, around 1107 UT. Near the region of interest the F12 satellite was within an extended region 1 current sheet in agreement with the F13 data. The satellite made a very brief excursion into the polar cap at around 11.04.30 UT, but then encountered a region of structured BPS electron precipitation with a range of energies. A clear boundary can be seen between the BPS and the harder, lower electron flux, 
F12

17 Dec 1996

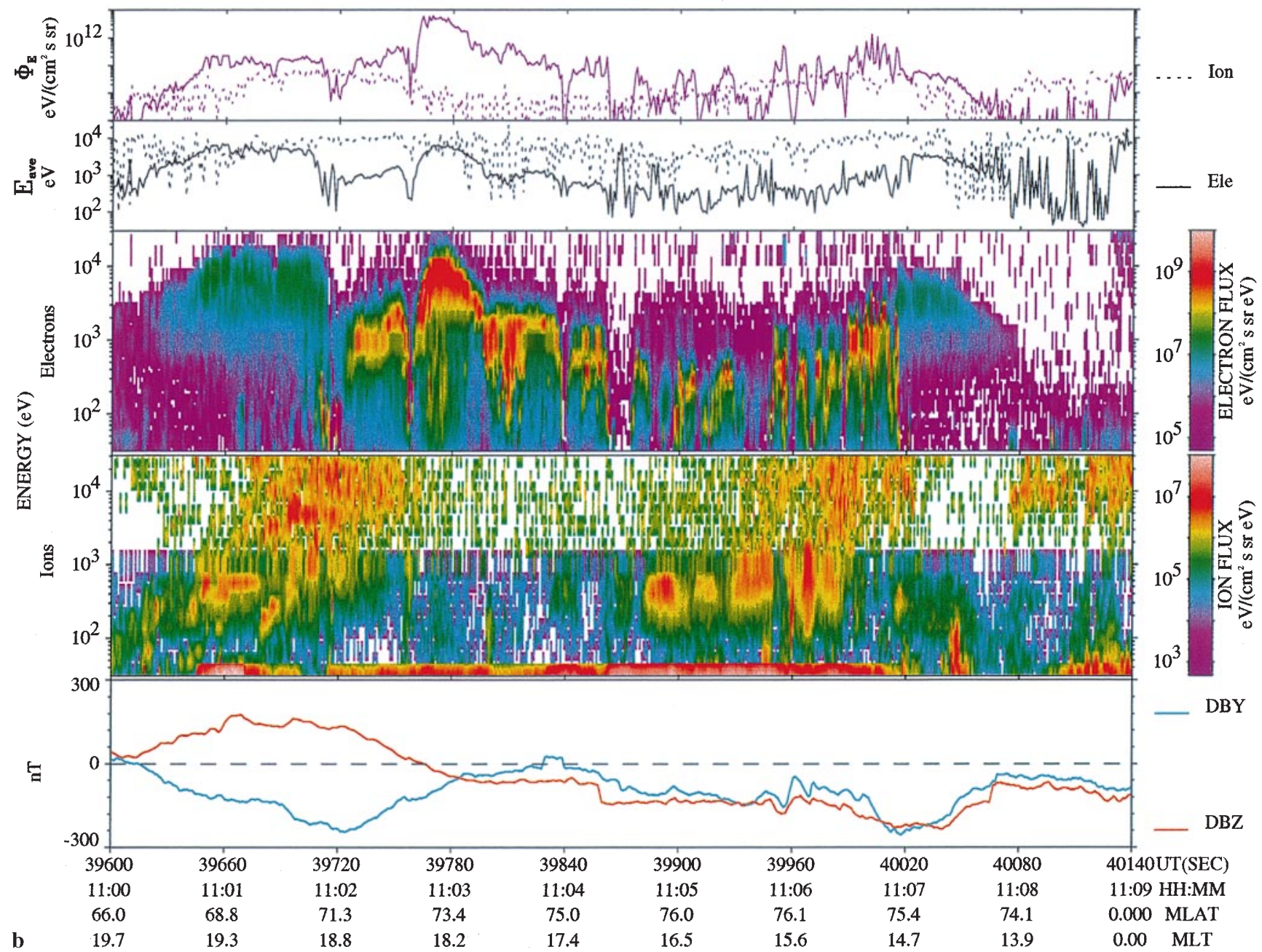

Fig. 3. Contd.

CPS precipitation, just before $1107 \mathrm{UT}$ at about $75.6^{\circ} \mathrm{N}$ MLAT.

The magnetospheric source of the plasma structures can be examined by comparing the nature of precipitation observed by the DMSP satellites with the structures seen in the tomographic reconstruction. Figure 4 shows the tracks of the DMSP passes and that of the tomographic image plane from the NIMS satellite, together with the scan of the MSP. The regions with different precipitation characteristics are indicated on the DMSP tracks. The location of the electron density enhancement is marked on the NIMS image plane, with the broader line at the equatorial limit showing the extent of the E-layer feature. The altitude-adjusted corrected geomagnetic (AACGM) co-ordinate system has been used for all of the observations. It is clear from the figure that, mapping approximately along $L$-shells, the auroral features and the plasma enhancement corresponds to the region of BPS precipitation. More specifically, the narrow, E-layer structure immediately north of $79^{\circ} \mathrm{N}$ in the tomographic image can be identified with the region where the energy of the electron input, measured by DMSP-F12 just before 1107 UT and by F13 after 1102
UT, maximised in the $\mathrm{keV}$ range. The modelling work of Roble and Rees (1977) demonstrated that electrons of such energies will give rise to ionisation in the E-region. The F-region, with discrete blobs around $79.5^{\circ} \mathrm{N}$ and $81^{\circ} \mathrm{N}$, can be mapped along the $L$-shells to the softer BPS electrons encountered by the DMSP satellites, again in accord with Roble and Rees (1977). It can be noted from Fig. 4 that DMSP-F13 encounters the BPS/polar-cap boundary at about $78^{\circ} \mathrm{N}$ MLAT at a universal time and a spatial location that are nearly coincident with the tomographic image plane. The boundary maps to about $81.5^{\circ} \mathrm{N}$ geographic, near to the northern limit of the discrete structuring seen in the plasma density. The smoother, elevated F-layer seen at the poleward extremity of the tomographic reconstruction may be related to low-energy precipitation of magnetosheath plasma within the polar cap.

\section{Discussion}

The work has demonstrated the ability of the tomographic technique to image features in the afternoon 


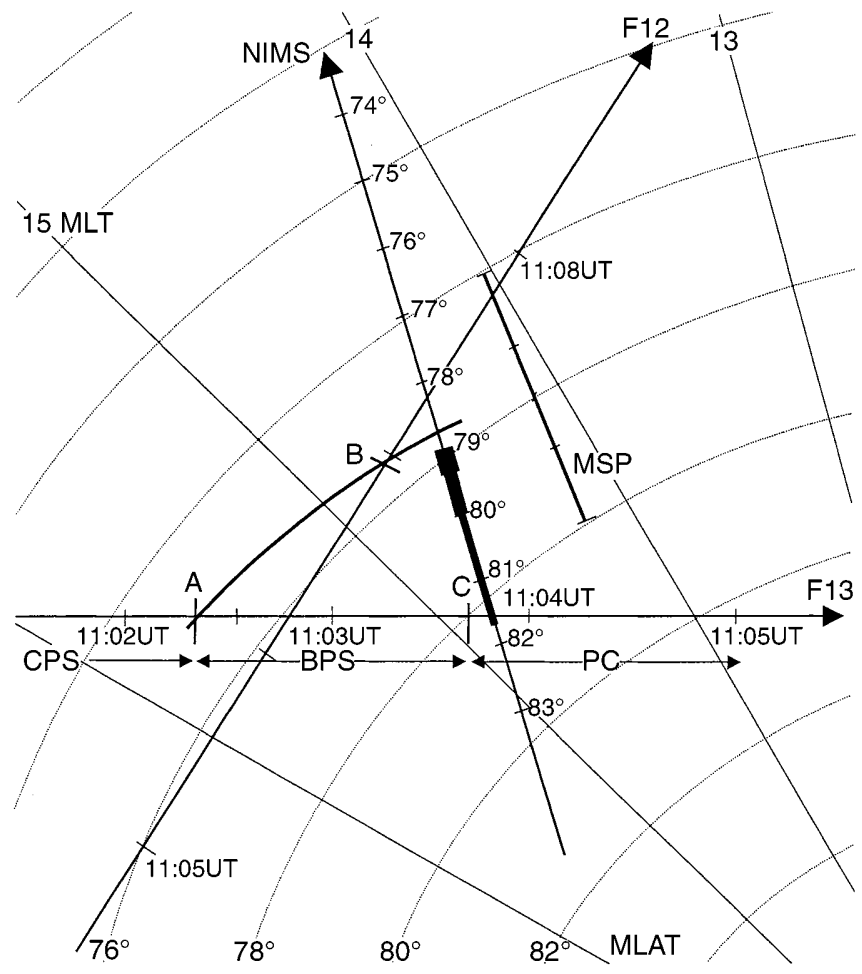

Fig. 4. Diagrammatic representation of the DMSP tracks, the NIMS satellite tomography image plane, and the scan of the meridian scanning photometer $(M S P)$ in the altitude-adjusted CGM latitude versus MLT plane. The locations of the $C P S / B P S$ boundary are marked by the letters $A$ and $B$ on the respective DMSP tracks, with $C$ denoting the BPS/polar cap $(P C)$ transition seen by satellite F-13. The locations of the structures in electron density are marked by the broadenings of the line on the image plane, with the widest segment near $79^{\circ} \mathrm{N}$ corresponding to the feature extending down to the E-region

auroral ionosphere that can be related to the precipitation of particles from the magnetosphere. Different regimes have been identified from the DMSP passes as sources for plasma structures within a confined latitudinal range: a very narrow region of harder particles that precipitate to E-layer altitudes, softer particles confined to the F-layer, and low-energy precipitation possibly of magnetosheath origin at the northern limit. The regimes seen in the particle observations correspond to distinct features in the plasma. The structures found between about $79^{\circ} \mathrm{N}$ and $81^{\circ} \mathrm{N}$ lie within the region of precipitation of BPS origin identified by DMSP, but differ in terms of the particle energies. Further north, there is a decreasing plasma density leading to an unstructured F-layer that corresponds to the region where the precipitation can be classified as of de-energised magnetosheath origin.

This suggestion of magnetosheath precipitation requires further discussion. It is possible that the change in character from the structured to the unstructured F-layer plasma, seen between $81^{\circ} \mathrm{N}$ and $82^{\circ} \mathrm{N}$ in the tomographic image, may delineate the flow-reversal boundary. The BPS auroral-linked plasma to the south is on sunward convecting field lines and, according to this interpretation, the flow in the region of magneto- sheath precipitation to the north would be anti-sunward on open flux tubes that map across the polar cap into the magnetotail on the nightside.

The convection flow vectors obtained from the magnetic perturbations measured by DMSP-F13, confirmed that the flow was sunward in the BPS region, with a reversal to the antisunward direction between 1103 UT and 1104 UT, in conformity to the BPS/polarcap boundary identified from the spectra. Thus the transition from structured to unstructured F-layer between $81^{\circ} \mathrm{N}$ and $82^{\circ} \mathrm{N}$ probably marks the convection reversal boundary. It can be noted that while this boundary may not be particularly dramatic in the current example, this may be because it is at the extremity of the image region, beyond the limit of the northernmost station of the tomographic chain. Examination of images from many other satellite passes in the sector shows that the poleward wall of the trough is usually highly structured but this gives way to a region of smoother plasma further north. The present work indicates that BPS precipitation is responsible for the fine structure immediately poleward of the trough, with a transition to to a smoother ionosphere being seen on crossing the convection reversal boundary further north.

The most striking feature of the tomographic image is the sharp boundary at $78^{\circ} \mathrm{N}$ to $79^{\circ} \mathrm{N}$ between the BPS auroral-related forms and the depleted trough region to the south. The DMSP satellite detectors show a clear boundary at the edge of the BPS region, leading to harder diffuse electron precipitation from the central plasma sheet. It can be seen from Fig. 4 that, particularly for DMSP-F12, this boundary maps well in both space and time to the poleward wall of the trough seen in the tomographic image. Thus, the steep gradient seen in the plasma density between $78^{\circ} \mathrm{N}$ and $79^{\circ} \mathrm{N}$ represents a signature in the ionosphere of the BPS/CPS transition.

A more detailed localised, version of image than is presented here indicates that underlying this F-layer dayside trough, which lies on the return flow in accord with Pryse et al. (1998), there is a closed contour in the electron density at about $100 \mathrm{~km}$ altitude, corresponding to a very weak E-layer between $77^{\circ} \mathrm{N}$ and $78^{\circ} \mathrm{N}$. It is possible that this structure may originate from the weaker, harder precipitation with a source in the central plasma sheet (CPS), but the certainty of its detection is at the current limit of the imaging technique.

The BPS precipitation identified here, that is linked to the latitudinally-narrow zone of plasma enhancement, is probably an extension from the nightside. Meng and Lundin (1986) showed examples of auroral forms originating on the nightside, but developing into latitudinally thin discrete filaments in the afternoon sector. The E-layer feature above $79^{\circ} \mathrm{N}$, with its field-aligned extension into the F-layer, may be a signature of an upward current sheet (Walker et al., 1998). Troshichev et al. (1996) have argued that the source of such region1 currents is close to the CPS/BPS boundary, in conformity with the present results. It can be noted that the observations shown here are probably too far removed from magnetic noon and the cusp, particularly as By is positive in this case, for the open-field line 
model of BPS precipitation proposed by Lockwood (1997) to apply.

Acknowledgements. Support is acknowledged from the UK Particle Physics and Astronomy Research Council under grant GR/ K98797. STB is funded by a PPARC Research Studentship. The assistance of colleagues in the Radio and Space Physics Group of the University of Wales, Aberystwyth is acknowledged with thanks, as is the help of the Norsk Polarinstittut at Ny Allesund and Professor T. Hansen and staff at the University of Tromsø for housing and monitoring the tomographic receivers. Support is acknowledged from the Norwegian Research Council and UNIS grant $9 / 963$. The optical observation programme of the University of Oslo at Ny Ålesund also receives technical support from the Norsk Polarinstittut.

The Editor in-Chief thanks T. K. Yeoman and H. C. Carlson for their help in evaluating this paper.

\section{References}

Evans, D. S., The characteristics of a persistent arc at high latitude in the 1400 MLT sector, The Polar Cusp, Ed. J. Holtet, and A. Egeland, D. Reidel, Norwell, Mass., pp 99-109, 1985.

Fremouw, E. J., J. A. Secan, and B. M. Howe, Application of stochastic inverse theory to ionospheric tomography, Radio Sci., 17, 721-732, 1992.

Gordon, R., R. Bender, and G. T. Herman, Algebraic reconstruction techniques (ART) for three-dimensional electron microscopy and X-ray photography, J. Theor. Biol., 29, 471-481, 1970.

Iijima, T., and T. A. Potemra, Large scale characteristics of fieldaligned currents associated with substorms, J. Geophys. Res., 83, 599-615, 1978.

Kersley, L., and S. E. Pryse, The development of experimental ionospheric tomography, Int. J. Image Syst. Technol., 5, 141-147, 1994.

Lockwood, M., Relationship of dayside auroral precipitations to the open-closed separatrix and the pattern of convective flow, J. Geophys. Res., 102, 17 475-17 487, 1997.

Meng, C. I., and R. Lundin, Auroral morphology of the midday oval, J. Geophys. Res., 91, 1572-1584, 1986.
Moen, J., P. E. Sandholt, M. Lockwood, A. Egeland, and K. Fukui, Multiple discrete arcs on sunward convecting field lines in the 14-15 MLT region, J. Geophys. Res., 99, 6113-6123, 1994.

Moen, J., S. T. Berry, L. Kersley, and B. Lybekk, Probing discrete auroral arcs by ionospheric tomography, Ann. Geophysicae, 16, 574-582, 1998.

Newell, P. T., and C-I. Meng, Mapping the dayside ionosphere to the magnetosphere according to particle precipitation characteristics, Geophys. Res. Lett., 19, 609-612, 1992.

Newell, P. T., W.J. Burke, E. R. Sanchez, C-I. Meng, M. E. Greenspan, and C. R. Clauer, The low-latitude boundary layer and the boundary plasma sheet at low altitude: dayside precipitation regions and convection reversal boundaries, J. Geophys. Res., 96, 21013-21023, 1991.

Pryse, S. E., L. Kersley, M. J. Williams, and I. K. Walker, The spatial structure of the dayside ionospheric trough, Ann. Geophysicae, 16, 1169-1179, 1998.

Robinson, R. M., D. S. Evans, T. A. Potemra, and J. D. Kelly, Radar and satellite measurements of an F-region enhancement in the post-noon sector, Geophys. Res. Lett., 9, 899-902, 1984.

Roble, R. G., and M. H. Rees, Time-dependent studies of the aurora: effects of particle precipitation on the dynamic morphology of ionospheric and atmospheric properties, Planet. Space. Sci., 25, 991-1010, 1977.

Sandholt, P. E., C. J. Farrugia, J. Moen, and B. Lybekk, The dayside aurora and its regulation by the interplanetary magnetic field, Polar cap boundary phenomena, Ed. Moen, J., Egeland, A. and Lockwood, M., Kluwer, Dordrecht, Netherland, pp 189-208, 1998.

Troshichev, O. A., E. M. Shishkina, G. Lu, and A. D. Richmond, Relationship of the ionospheric convection reversal to the hard auroral precipitation boundary, J. Geophys. Res., 102, 1542315432, 1996

Walker, I. K., J. A. T. Heaton, L. Kersley, C. N. Mitchell, S. E. Pryse, and M. J. Williams, EISCAT verification in the development of ionospheric tomography, Ann. Geophysicae, 14, 1413-1421, 1996.

Walker, I. K., J. Moen, C. N. Mitchell, L. Kersley, and P. E. Sandholt, Ionospheric effects of magnetopause reconnection observed using ionospheric tomography, Geophys. Res. Lett., 25, 293-296, 1998. 